\title{
Effects of alkyl ethyl sulfonate dosage on cotton defoliation efficacy sprayed by UAV
}

\author{
Qinggang Xiao ${ }^{1}$, Rui Du ${ }^{1}$, Tingting Zhou ${ }^{1}$, Xiaogiang $\mathrm{Han}^{1 *}$, Guobin Wang ${ }^{2}$, Wei Fu ${ }^{3}$ \\ (1. College of Agriculture / Key Laboratory of Oasis Agricultural Pest Management and Plant Protection Resources Utilization, \\ Shihezi University, Shihezi, 832002, China; \\ 2. College of Agricultural Engineering and Food Science / Shandong Provincial Engineering Technology Research Center for \\ Agricultural Aviation Intelligent Equipment, Shandong University of Technology, Zibo, 255022, China; \\ 3. College of Mechanical and Electrical Engineering, Hainan University, Haikou, 570228, China)
}

\begin{abstract}
As a new low volume sprayer, unmanned aerial vehicle (UAV) application is developing quickly worldwide. Alkyl ethyl sulfonate soluble concentrate is a kind of spray adjuvants for defoliants, which is widely used in cotton defoliant application. The aim of this study was to compare the droplet deposition, defoliation and boll opening of a UAV added with six dosages of alkyl ethyl sulfonate on the cotton. Addition with $4.2 \mathrm{~g}$ a.i. $/ \mathrm{hm}^{2}$ (one-sixtieth of the recommended dosage in the field) alkyl ethyl sulfonate could significantly increase the droplets coverage rate, and improve defoliation and boll opening effects. Added with lower dosage alkyl ethyl sulfonate $\left(4.2 \mathrm{~g}\right.$ a.i. $/ \mathrm{hm}^{2}$ and $8.4 \mathrm{~g}$ a.i. $\left./ \mathrm{hm}^{2}\right)$, the droplet distribution uniformity was much better than that of moderate $\left(84 \mathrm{~g}\right.$ a.i. $\left./ \mathrm{hm}^{2}\right)$ and high dosage $\left(252 \mathrm{a} . \mathrm{i} . / \mathrm{hm}^{2}\right)$ of alkyl ethyl sulfonate. It could not only ensure the effects of defoliation and boll opening, but also reduce the environmental pollution by alkyl ethyl sulfonate.
\end{abstract}

Keywords: defoliant, alkyl ethyl sulfonate dosage, droplet deposition, unmanned aerial vehicle

DOI: $10.33440 /$ j.ijpaa.20190202.33.

Citation: Xiao Q G, Du R, Zhou T T, Han X Q, Wang G B, Fu W. Effects of alkyl ethyl sulfonate dosage on cotton defoliation efficacy sprayed by UAV. Int J Precis Agric Aviat, 2019; 2(2): 67-75.

\section{Introduction}

Cotton (Gossypium hirsutum L.) is an important raw material for textile industry. The quality of cotton is directly related to the product quality and production efficiency of textile enterprises ${ }^{[1]}$. Xinjiang has the natural conditions and resource advantages of planting cotton. In 2018, the area used for cotton planting reached 2.49 million ha, accounting for $74.32 \%$ of the cotton planting area in China, and the total output of cotton is 5.11 million tons, accounting for $83.84 \%$ of the cotton production in $\mathrm{China}^{[2]}$. Developing the machine-harvested cotton is conducive to realizing large-scale operation, greatly reducing cotton planting costs, improving labor productivity, and promoting the transformation of cotton production to modern agriculture ${ }^{[3]}$. In 2018, the planting area of machine-picked cotton reached 870,000 ha in Xinjiang, China $^{[4]}$. The application of chemical defoliants is a key technology for the machine-harvested cotton. A high leaf defoliation rate is obtained when chemical defoliant is applied at the $40 \%-60 \%$ boll open stage ${ }^{[5,6]}$. However, temperatures are unstable in the Xinjiang cotton belt, with minimum temperatures dropping sharply in early autumn ${ }^{[7]}$. Under these conditions, the defoliants have to be sprayed early to facilitate machine harvesting.

\section{Received date: 2019-11-26 Accepted date: 2019-12-15}

Biographies: Qinggang Xiao, Master student, research interest: pesticide application technology, Email: xqg@stu.shzu.edu.cn; Rui Du, Master student, research interest: pesticide application technology, Email: rd@stu.shzu.edu.cn; Tingting Zhou, Master student, research interest: pesticide toxicology, Email: ztt@stu.shzu.edu.cn; Guobin Wang, PhD, lecturer, research interest: precision agricultural aviation application, Email: guobinwang@stu.scau.edu.cn; Wei Fu, $\mathrm{PhD}$, Professor, research interest: agricultural engineering, Email: fuwei001@ 126.com.

*Corresponding author: Xiaoqiang Han, PhD, Associate Professor, research interest: pesticide application technology, Email: hanshz@shzu.edu.cn.
Early defoliation adversely affects boll components and fiber development and significantly increases the percent of immature bolls and lint mass ${ }^{[8]}$. These reductions in fiber quality had caused declines in the sale of machine-harvested cotton from Xinjiang ${ }^{[9]}$. Therefore, improving the defoliation effect and reducing the impurities in broken leaves of seed cotton are the key to achieving high quality and high efficiency of machine-harvested cotton.

The highly density planting pattern has potential and prospects in oasis agriculture in Xinjiang. However, the cotton leaves overlap considerably. Boom sprayers are widely used for large farm crops due to their high working efficiency and effective spraying. As ground machinery, the boom sprayer spraying leads to problems, such as rolling cotton plants, hitting cotton bolls and pulling cotton branches, which reduce the yield and quality of cotton $^{[10,11]}$. To adapt to this unique operating environment and improve the shortage of the defoliants spraying equipment supply, unmanned aerial vehicles (UAVs) have been rapidly developed in Xinjiang, China for pesticide application ${ }^{[12-15]}$. According to the statistics provided by the Ministry of Agriculture and Rural Affairs of the People's Republic of China, nearly 30,000 crop protection UAVs are used in the country ${ }^{[16,17]}$. The spraying area of cotton defoliants approached 6.7 million hectares in $2018^{[4]}$. Compared with boom sprayer, UAVs spraying cotton defoliant could avoid seed cotton yield loss of more than $6 \%$, which display significant economic benefits ${ }^{[18]}$. At present, the study on the cotton defoliants spraying by UAVs mainly focused on the feasibility of spraying operation, that is, after cotton defoliant spraying by UAVs, the spraying quality were judged by the effect of cotton defoliation rate and boll opening rate. In 2016, in order to study the effect of UAV spraying cotton defoliant, and then selected the spraying parameters suitable for UAV spraying cotton defoliant, the National Aviation Plant Protection Science Technology Innovation 
Alliance (NAPP) organized a joint test of UAVs spraying cotton defoliant in Shihezi, Xinjiang. That was the first large-scale joint test of UAVs spraying cotton defoliant in China, which has a positive significance for the promotion of $\mathrm{UAVs}^{[19]}$. Since then, UAVs spray cotton defoliant developed rapidly. Wang et $\mathrm{al}^{[20]}$ and $\mathrm{Hu}$ et $\mathrm{al}^{[21]}$ screened the defoliants suitable for UAV spraying. Zhang et $\mathrm{al}^{[22]}$ and Xin et $\mathrm{al}^{[14]}$ reported that UAV spraying cotton defoliants could achieve efficient utilization of the defoliants. Hu et $\mathrm{al}^{[15]}$ and Wen et $\mathrm{al}^{[23]}$ found that the efficiency of UAV spraying cotton defoliant was significantly higher than that of electric air-pressure knapsack (EAP) and boom sprayer. Xiao et al ${ }^{[13]}$ and Meng et $\mathrm{al}^{[12]}$ found that vegetable oil adjuvants had significant effects on improving the deposition of droplets and increasing the efficacy of defoliants. These studies had played a great role in promoting the development of cotton defoliant spraying technology by UAVs in Xinjiang cotton belt.

Alkyl sulfonates are an anionic surfactant with good wetting, spreading and penetration characteristic. Alkyl sulfonates are used predominantly in pesticide ${ }^{[24]}$, medicine ${ }^{[25]}$, detergents ${ }^{[26]}$, petroleum industry ${ }^{[27]}$ and textile industry ${ }^{[28]}$. These chemicals show low acute and repeat dose toxicity ${ }^{[29]}$. However, the large number of alkyl sulfonate compounds could be form negative charged micelles in water, forth, covering the water surface, affecting the transmission of oxygen, reducing the amount of dissolved oxygen in water, which resulting in deterioration of water quality and affecting the growth of aquatic organisms ${ }^{[30]} .280 \mathrm{~g} / \mathrm{L}$ alkyl ethyl sulfonate soluble concentrate is a kind of spray adjuvants for cotton defoliants, which widely used in Xinjiang. It could increase the wettability and permeability of defoliants on cotton leaves, improve the penetration rate, and reduce the negative effects of droplet drift and bounce, and improve the utilization rate of pesticides. However, in the current production, the recommended dosage of the alkyl ethyl sulfonate, is used for boom sprayer. Dosage of alkyl ethyl sulfonate used for UAVs spraying cotton defoliant is blank. For UAVs, the spray volume is only one-twentieth of that of boom sprayer, but there is no corresponding decrease in the use of alkyl ethyl sulfonate. This would not only cause waste of resources, but also bring great pollution to the environment. Herein, we report our results concerning the effect of alkyl ethyl sulfonate adjuvants on droplet deposition, defoliation and boll opening sprayed by a UAV. The purpose of this study was to provide scientific support for reducing defoliants and increase efficiency in Xinjiang.

\section{Materials and methods}

\subsection{Spray equipment}

A battery motive P30 four-rotor UAV (XAG Co., Ltd., Guangzhou, China) (Figure 1) was used in this study. The UAV was powered by a $12800 \mathrm{mAh}$ Li-Po battery (XAG Co., Ltd., Guangzhou, China). The flying time was 15 min with full tank. The flight speed was $14.4-43.2 \mathrm{~km} / \mathrm{h}$. The interval of nozzles (iRASS intelligent centrifugal spraying technology, with a nozzle flow range of 2.7 to $5.6 \mathrm{~L} / \mathrm{min}$, droplet size $90-300 \mu \mathrm{m}$ ) was $1.18 \mathrm{~m}$ and the installation angle was vertically downward. The pesticide was transferred from the tank to the nozzles by a high frequency pulse peristaltic pump (XAG Co., Ltd., Guangzhou, China). The accuracy of the flying height and flying velocity was controlled in centimeter-level with the help of real time kinematic differential positioning technology. The flight height was $2.0 \mathrm{~m}$ and the effective spraying width was $3.5 \mathrm{~m}$. The spray volume was close to $15 \mathrm{~L} / \mathrm{hm}^{2[13]}$.

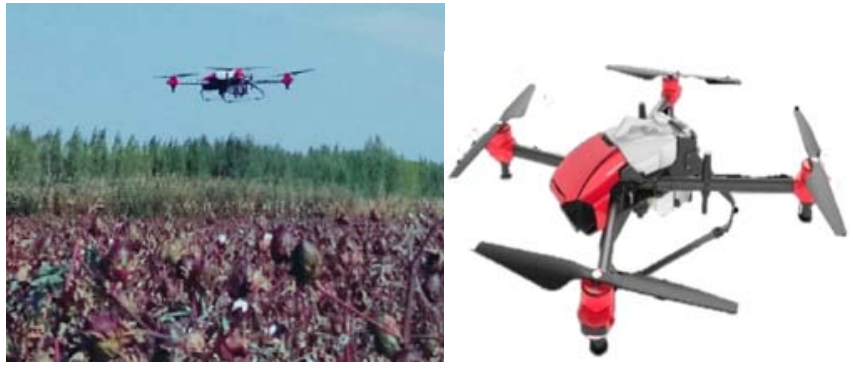

Figure 1 P30 electric four-rotor plant protection UAV

\subsection{Experiment design}

\subsubsection{Field plots}

The experiments were conducted at the town of Beiquan, Xinjiang Production and Construction Crops, Shihezi, Xinjiang

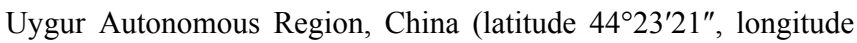
$\left.85^{\circ} 58^{\prime} 48^{\prime \prime}\right)$. The test cotton material was "Hexin 47", which was sown on 28 April, 2018, using a machine-harvested cotton planting model with wide film planting 6 lines $(10 \mathrm{~cm}+66 \mathrm{~cm}), 192,000$ cotton plants/ha, and drip irrigation under plastic film. The cotton in the whole test area grew well and consistently.

\subsubsection{Spray-deposition measurements}

According to the dosage of alkyl ethyl sulfonate (BIOPOWER $\AA$ ) (Bayer Crop Science Co., Ltd., Leverkusen, Germany), the experiment consists of six treatments: $0,4.2,8.4,84,168,252 \mathrm{~g}$ a.i. $/ \mathrm{hm}^{2}$ (active ingredient/ha, which $252 \mathrm{~g}$ a.i./ $/ \mathrm{hm}^{2}$ was the recommended dosage for the boom sprayer application). The droplets deposition, defoliation, boll opening, defoliant retention in cotton leaves and cotton yield characteristic and fiber quality were tested.

The spray deposition and the control efficacy were measured in a $109 \mathrm{~m} \times 150 \mathrm{~m}$ area (Figure 2A). The sample layout was repeated three times, $20 \mathrm{~m}$ apart between adjacent repetitions. Each plot was a $14 \mathrm{~m} \times 150 \mathrm{~m}$ area. 5-m buffer zones were set between plots to avoid drift pollution (Figure $2 \mathrm{~A})^{[31]}$. Sample collectors at each sample site consisted of one water-sensitive papers (WSPs; $25 \mathrm{~mm} \times 75 \mathrm{~mm}$; Figure 2B). The WSPs were used to evaluate the deposition characteristics such as droplet coverage rare and droplet size ${ }^{[32,33]}$. The WSPs were fixed to cotton leaves using paper clips ${ }^{[13]}$.

Defoliation treatments were initiated at $40 \%$ boll opening time ${ }^{[5,6]}$. The first defoliant spraying was conducted on 15 September 2018, and the second defoliant spraying was conducted on 22 September 2018. The climatic condition was recorded using a Kestrel 5500 digital meteorograph (Loftopia, LLC, USA). The recorded temperatures of $19.5-30.5^{\circ} \mathrm{C}$, a relative humidity of $17.8-31.3 \%$ and wind velocities of $0-14.4 \mathrm{~km} / \mathrm{h}$ on 15 September 2018. The recorded temperatures of $22.0-35.9^{\circ} \mathrm{C}$, a relative humidity of $18.7-43.0 \%$ and wind velocities of $0-14.04 \mathrm{~km} / \mathrm{h}$ on 22 September 2018. There was no precipitation during the defoliation spraying.

In all tests, $360 \mathrm{~g} / \mathrm{L}$ thidiazuron $180 \mathrm{~g} / \mathrm{L}$ diuron suspension concentrate (Drop ultra) at $121.5 \mathrm{~g}$ a.i./ha (Bayer Crop Science Co., Ltd., Leverkusen, Germany) and $40 \%$ ethephon at $480 \mathrm{~g}$ a.i./ha (September 22, 2018 was 600 g a.i. /ha) (Jiangsu Anpon Electrochemical Co., Ltd., Huaian, China) were added into the tank.

Nearly $30 \mathrm{~s}$ after spraying, all WSPs were removed and placed in self-sealing bags along with a label describing the treatment, replication, and WSPs site information. For each plot, there were $21 \mathrm{WSPs}^{[13]}$. Samples were placed into light-proof sealed boxes immediately after collection and transported to the laboratory for analysis. In the laboratory, the WSPs were scanned at a resolution 
of 600 dpi with a scanner. After that, Image $\mathrm{J}$ software (Image J 1.3 8, National Institutes of Health, Bethesda, MD, USA) was used to extract droplet deposits in the digital image for the analysis of the droplet size, number of spray deposits and the area of coverage. Coverage was determined as the percent cover of the card from the stain of the deposited image ${ }^{[34]}$. The distribution uniformity of the spray deposition in the cotton canopy was analyzed using the value corresponding to the coefficient of variation $(\mathrm{CV})$, calculated as the quotient between the standard deviation and the average of the spray deposits on the cotton ${ }^{[31]}$.

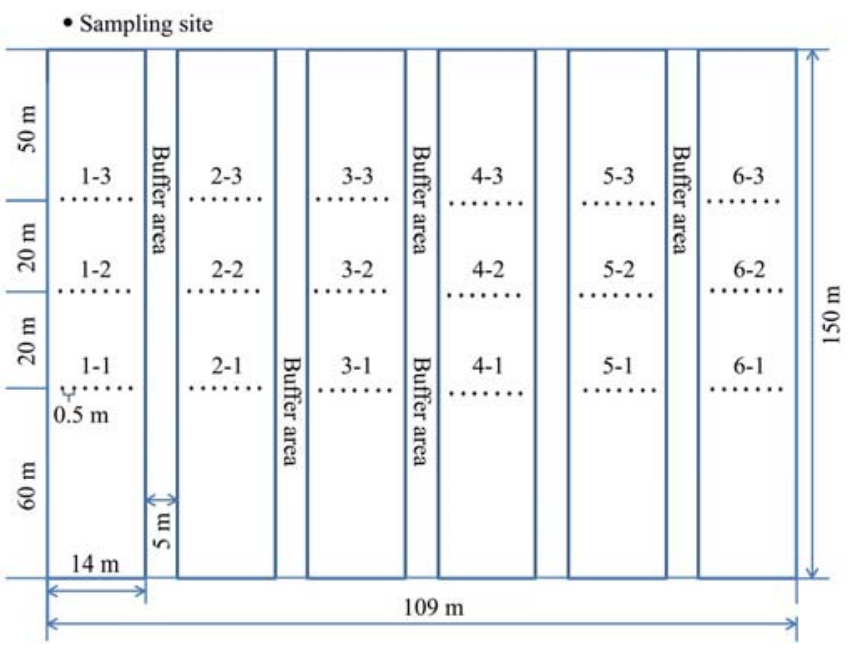

A

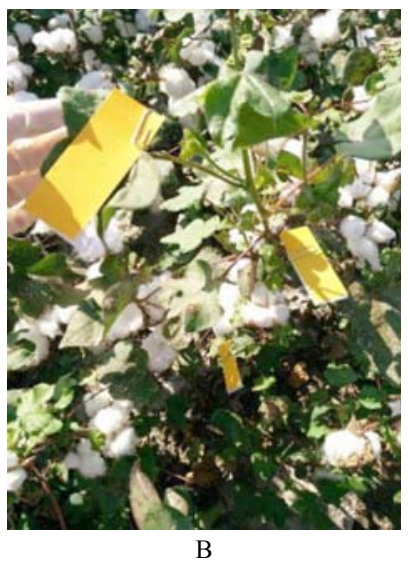

Figure 2 (A) Experimental layout of each treatment and (B) placement of water-sensitive papers (WSPs) at each sampling position within the cotton canopy

\subsubsection{Contact angle}

The contact angle was measured from $0^{\circ}$ to $180^{\circ}$ and the measurement accuracy is $\pm 0.1^{\circ}$. Collected the fresh and clean cotton inverted three leaves, selected the flat part to cut the small leaf surface (to avoid veins, disease spots, etc.) and lay it flat in the sample slot of the contact angle instrument. Using a micro syringe to draw each solution respectively, and drop $4 \mu \mathrm{L}$ of the solution on the cotton leaf surface. The contact angle was observed 30 seconds later and repeated 10 times. The average and standard deviation were calculated.

\subsubsection{Defoliation and boll opening}

The cotton defoliation rate and the boll opening rate were chosen as the field test targets to analyze the field efficacy of alkyl ethyl sulfonate dosage with different spray deposition characteristics. Defoliation rate and boll opening rate were selected based on previous reports ${ }^{[13,14]}$. Prior to treatment application, 30 cotton plants were randomly tagged to count the number of leaves on each cotton plant. The number of leaves were investigated and recorded four times according to defoliant field efficacy test criteria (4, 7, 12 and 15 days after spraying). The defoliation rate was calculated using Equation (1): Defoliation rate $(\%)=\left(\left(N_{a}-N_{b}\right) / N_{a}\right) \times 100 \%$

where, $N_{a}$ is the number of leaves before treatment and $N_{b}$ is the number of leaves after treatment.

Boll opening rate was determined on the same tagged 30 cotton plants. The number of cotton bolls (opened and closed) were investigated and recorded four times according to defoliant field efficacy test criteria (4, 7, 12 and 15 days after spraying). Boll opening rate was calculated by:

$$
\text { Boll opening rate }(\%)=\left(N_{c} / N_{d}\right) \times 100 \%
$$

where, $N_{c}$ is the number of opened bolls and $N_{d}$ is the total number of bolls.

\subsubsection{Cotton yield characteristics and fiber quality}

The cotton bolls weight was measured after all the cotton bolls opened. For this measurement, 50 cotton bolls from the canopies (upper, middle and lower layers) were randomly collected in each experimental area to determine the bolls weight and fiber quality (determined by the Key Laboratory of Cotton Biology and Genetics and Breeding in the Northwest Inland Region of the Ministry of Agriculture, Shihezi, China) ${ }^{[13]}$.

\subsection{Data statistics and processing}

The percentage of the area covered on the WSP, defoliation rate and boll opening rate, were transformed to arcsin $\sqrt{ } \mathrm{X} / 100$. The deposition on different canopies, number of spray deposits and droplet size were $\log (x+1)$ transformed prior to analysis in order to stabilize the wide variances and meet normal assumptions. After transformation, the data were analyzed for normality using the Kolmogorov-Smirnov test and for equal variance across the treatments and replicates using Levene's test $(p<0.05)$. Data were compared across different application rates using analysis of variance (ANOVA) (Origin 9.1 originLab, Northampton, MA, USA). By comparing the mean one-way ANOVA, the least significant difference (LSD) was selected. The confidence interval was set to $95 \%$ and $p<0.05$ was chosen to indicate a significant difference between the two groups.

\section{Results and discussion}

\subsection{Spray deposition}

\subsubsection{Droplet coverage rate}

To obtain a satisfactory defoliation efficiency, it is meaningful to optimize the dosage of alkyl ethyl sulfonate to obtain better droplet coverage and penetration. As shown in Figure 3, the droplets average coverage rate without alkyl ethyl sulfonate was only $0.85 \%$ (Figure $3 \mathrm{a}$ ), while that of spraying with alkyl ethyl sulfonate was $2.01 \%$. These results indicated that the average droplet coverage ratewith alkyl ethyl sulfonate was significantly higher than that without alkyl ethyl sulfonate. When the added dosage of alkyl ethyl sulfonate was $4.2 \mathrm{~g}$ a.i. $/ \mathrm{hm}^{2}$ (one-sixtieth of the recommended dosage in the field) and $8.4 \mathrm{~g}$ a.i. $/ \mathrm{hm}^{2}$ (one-thirtieth of the recommended dosage in the field), the average droplet coverage rate was $1.56 \%$ and $1.92 \%$, respectively (Figure $3 \mathrm{~b}$ and $3 \mathrm{c}$ ). When the added dosage of alkyl ethyl sulfonate was $84 \mathrm{~g}$ a.i. $/ \mathrm{hm}^{2}$ (one-third of the recommended dosage in the field) and $168 \mathrm{~g}$ a.i. $/ \mathrm{hm}^{2}$ (a half of the recommended dosage for boom sprayer), the droplet average coverage rate after the first spraying was $3.26 \%$ and $2.38 \%$, respectively. After the second spraying, the average droplet coverage rate reached $2.31 \%$ and $2.35 \%$ respectively. These results showed the average droplet coverage 
rate after the second spraying was significantly higher than that of other treatments (Figure 3d and Figure 3e). At the recommended dosage in the field (252 $\mathrm{g}$ a.i. $\left./ \mathrm{hm}^{2}\right)$, the defoliant droplet coverage was $1.50 \%$ (Figure $3 \mathrm{f}$ ).

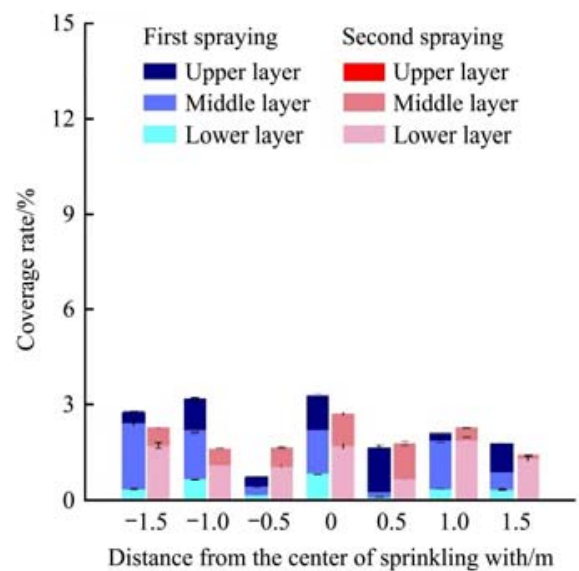

a. $0 \mathrm{~g}$ a.i. $/ \mathrm{hm}^{2}$

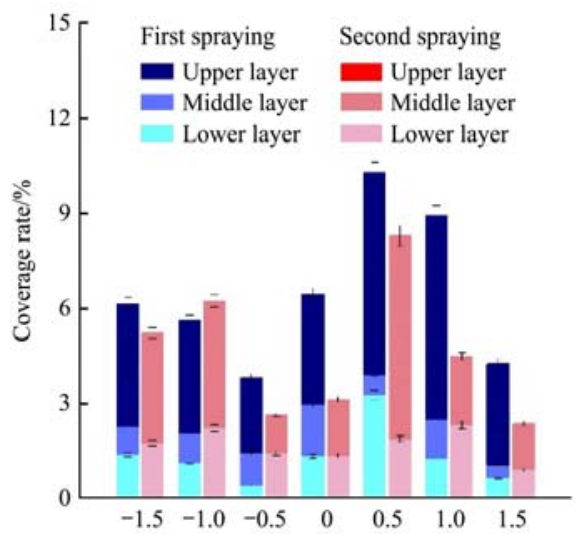

Distance from the center of sprinkling with $/ \mathrm{m}$

d. $84 \mathrm{~g}$ a.i. $/ \mathrm{hm}^{2}$

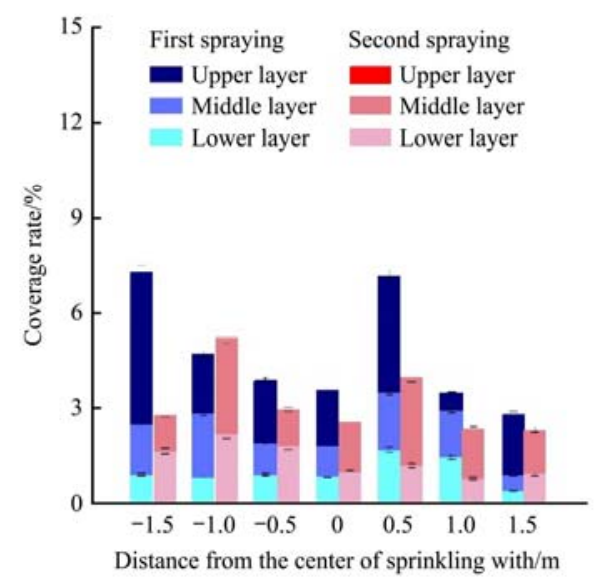

b. $4.2 \mathrm{~g}$ a.i. $/ \mathrm{ham}^{2}$

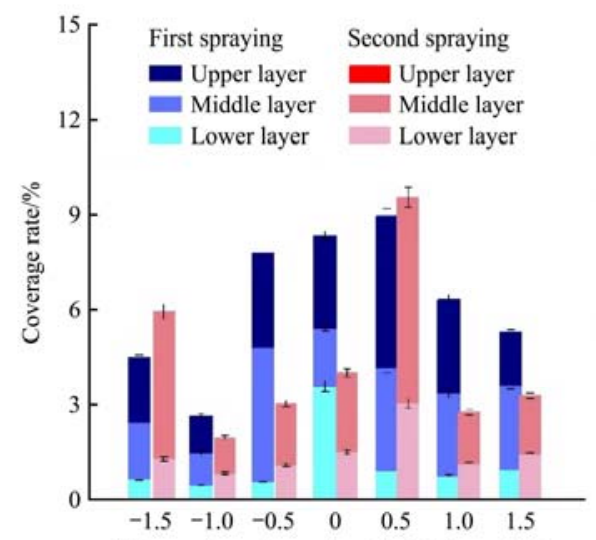

Distance from the center of sprinkling with $/ \mathrm{m}$

e. $168 \mathrm{~g}$ a.i. $/ \mathrm{hm}^{2}$

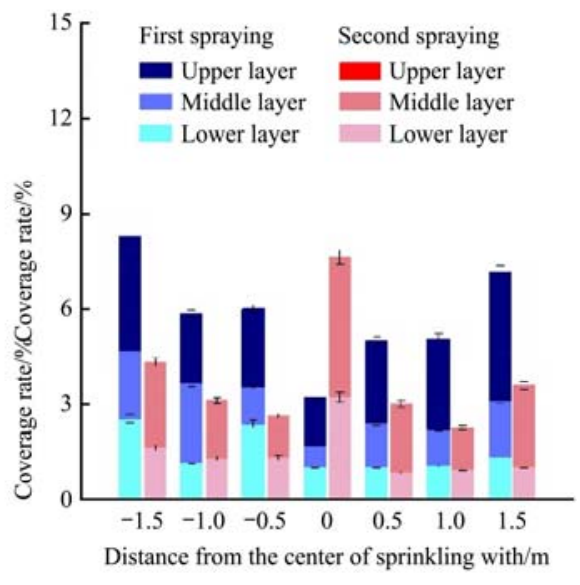

c. $8.4 \mathrm{~g}$ a.i. $/ \mathrm{hm}^{2}$

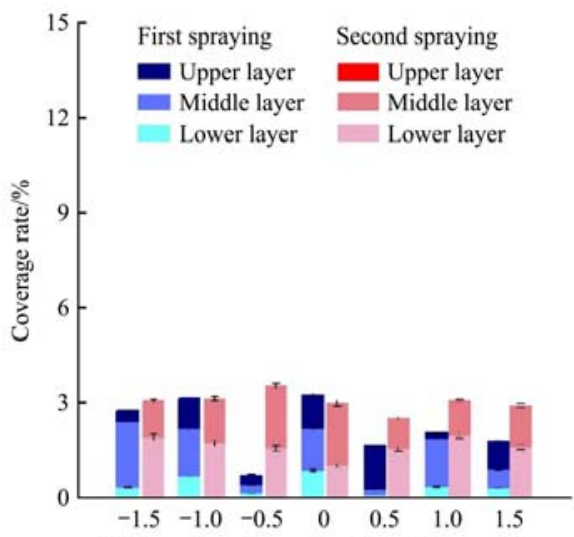

Distance from the center of sprinkling with $/ \mathrm{m}$

$$
\text { f. } 252 \mathrm{~g} \text { a.i. } / \mathrm{hm}^{2}
$$

Figure 3 Effect of alkyl ethyl sulfonate dosage on droplets coverage rate.

\subsubsection{Droplet density}

As shown in Figure 4, the effect of alkyl ethyl sulfonate dosage on cotton droplet density was similar to that of droplet coverage rate. When added alkyl ethyl sulfonate as 4.2, 8.4, 84, $168 \mathrm{~g}$ a.i. $/ \mathrm{hm}^{2}$, the average droplet density was 20.9 droplets $\mathrm{cm}^{-2}$. The control treatment (Figure 4a) and added alkyl ethyl sulfonate as $252 \mathrm{~g}$ a.i. $/ \mathrm{hm}^{2}$ (Figure $4 \mathrm{f}$ ), the average droplet density was 11.25 droplets $\mathrm{cm}^{-2}$ and 15.25 droplets $\mathrm{cm}^{-2}$, respectively. With the addition of $4.2 \mathrm{~g}$ a.i. $/ \mathrm{hm}^{2}$ alkyl ethyl sulfonate, the average droplet density after the first spraying reached 20.77 droplets $\mathrm{cm}^{-2}$ (Figure $4 b$ ), while the average droplet density of others was less than 20 droplets $\mathrm{cm}^{-2}$. After the second spraying, the average droplet density reached 28.95 droplets $\mathrm{cm}^{-2}\left(4.2 \mathrm{~g}\right.$ a.i. $\left./ \mathrm{hm}^{2}\right)$, 27.74 droplets $\mathrm{cm}^{-2}\left(8.4 \mathrm{~g}\right.$ a.i. $\left./ \mathrm{hm}^{2}\right), 28.33$ droplets $\mathrm{cm}^{-2}$ (84 g a.i. $\left./ \mathrm{hm}^{2}\right)$ and 28.84 droplets $\mathrm{cm}^{-2}\left(168 \mathrm{~g}\right.$ a.i. $\left./ \mathrm{hm}^{2}\right)$, respectively. The control treatment (Figure 4a) and added alkyl ethyl sulfonate as $252 \mathrm{~g}$ a.i. $/ \mathrm{hm}^{2}$ (Figure $4 \mathrm{f}$ ), the average droplet density was 10.38 droplets $\mathrm{cm}^{-2}$ and 11.39 droplets $\mathrm{cm}^{-2}$, respectively. The results showed that the addition of alkyl ethyl sulfonate had a significant effect on droplet density, and the droplet density in cotton canopy was the most significant when the addition amount was $4.2 \mathrm{~g}$ a.i. $/ \mathrm{hm}^{2}$.

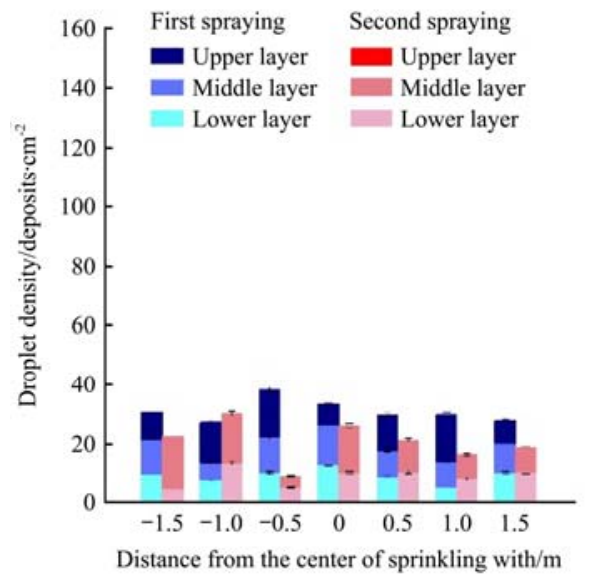

a. $0 \mathrm{~g}$ a.i. $/ \mathrm{hm}^{2}$

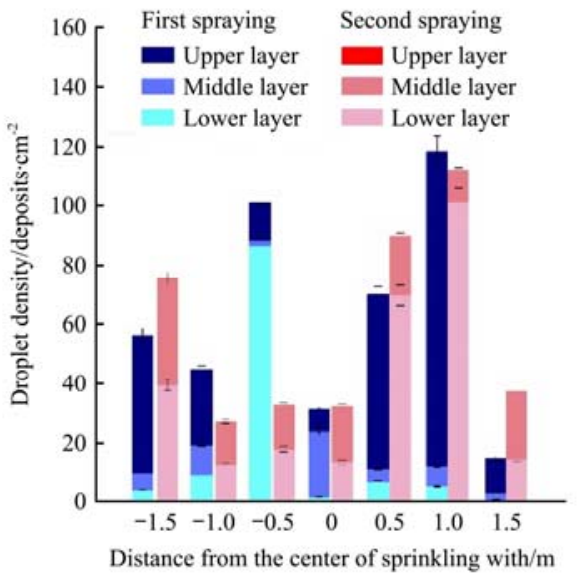

b. $4.2 \mathrm{~g}$ a.i. $/ \mathrm{ham}^{2}$

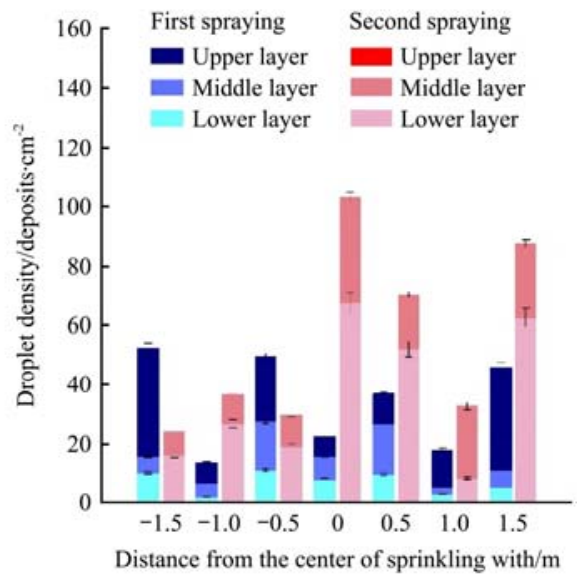

c. $8.4 \mathrm{~g}$ a.i. $/ \mathrm{hm}^{2}$ 


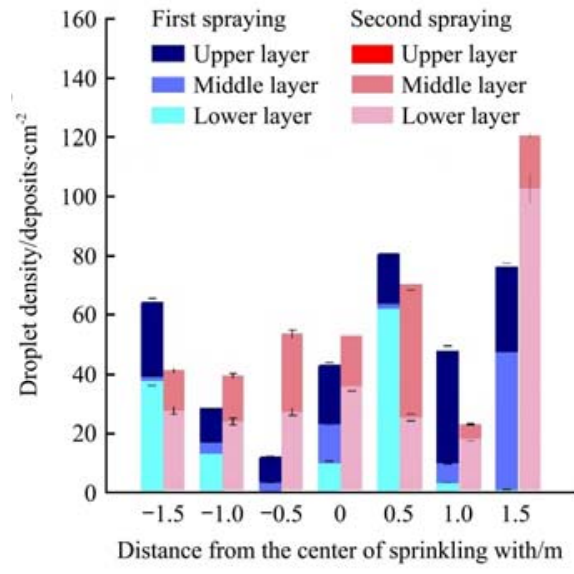

d. $84 \mathrm{~g}$ a.i. $/ \mathrm{hm}^{2}$
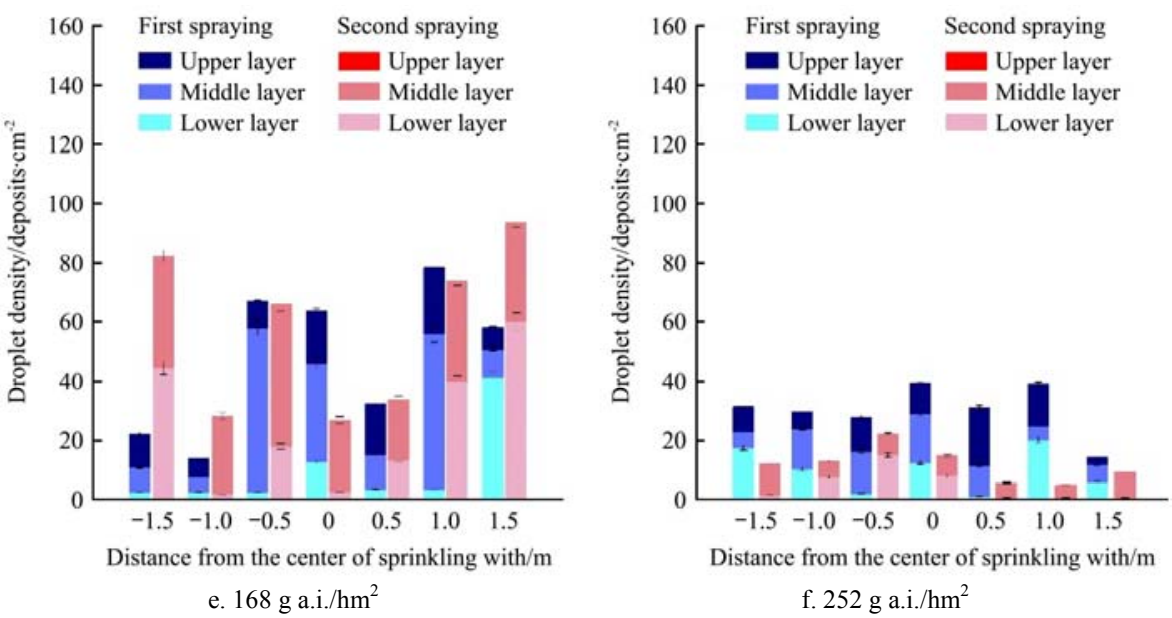

Figure 4 Effect of alkyl ethyl sulfonate dosage on droplets density

The size, number and concentration of droplets had an important influence on the field efficacy of pesticide ${ }^{[35]}$. Table 1 showed the effect of alkyl ethyl sulfonate on the defoliant droplets size on cotton leaves. The droplet size of defoliant increased significantly with alkyl ethyl sulfonate, which was significantly higher than that without alkyl ethyl sulfonate. The result showed that alkyl ethyl sulfonate had excellent plate-out ability. The droplet size of the control treatment was smaller $\left(\mathrm{Dv}_{50}<200 \mu \mathrm{m}\right)$, which could easily cause droplet evaporation and drift, resulting in lower droplet density and coverage rate. Zhang et al found that the type and concentration of adjuvant had a great influence on the droplet size ${ }^{[36]}$. Lan et al found that addition of a spray adjuvant resulted in significantly lower airborne $\mathrm{drift}^{[37]}$. Meanwhile, the adjuvants had a considerable influence on the efficiency ${ }^{[38]}$. This is probably due to the improvement of the wetting and extending properties of defoliant droplets on the water sensitive paper, resulting in a large reading droplet size.

\subsubsection{Uniformity of the deposition}

To comprehensively evaluate the droplet deposition distribution in the cotton canopy, the coefficient of variation $(\mathrm{CV})$ of the droplet deposition characteristics (droplet density and coverage rate) was calculated to characterize the droplet distribution uniformity after the addition of alkyl ethyl sulfonate (Table 2). For low volume spraying, the relevant quality indicators could be achieved when the droplet distribution uniformity is less than $60 \%{ }^{[39]}$. The results showed that the $C V$ of droplet distribution was more than $60 \%$ added with moderate dosage alkyl ethyl sulfonate $\left(84 \mathrm{~g}\right.$ a.i. $/ \mathrm{hm}^{2}, 168 \mathrm{~g}$ a.i. $/ \mathrm{hm}^{2}$ and $252 \mathrm{~g}$ a.i. $/ \mathrm{hm}^{2}$ ). When added with $4.2 \mathrm{~g}$ a.i. $/ \mathrm{hm}^{2}$ and $8.4 \mathrm{~g}$ a.i. $/ \mathrm{hm}^{2}$ alkyl ethyl sulfonates, the $C V$ was $47.9 \%$ and $55.39 \%$, respectively. The results showed that added with lower dosage alkyl ethyl sulfonate, the droplet distribution uniformity was much better than that of moderate and high dosage alkyl ethyl sulfonate.

Table 1 Effects of alkyl ethyl sulfonate dosage on droplets size

\begin{tabular}{ccccc}
\hline \multirow{2}{*}{$\begin{array}{c}\text { Date of } \\
\text { spraying }\end{array}$} & $\begin{array}{c}\text { Alkyl ethyl sulfonate } \\
\text { dosage/g a.i. } \mathrm{hm}^{-2}\end{array}$ & \multicolumn{3}{c}{$\mathrm{D}_{\mathrm{V} 50} / \mu \mathrm{m}$} \\
\cline { 3 - 5 } & 0 & Upper layer & Middle layer & Lower layer \\
\hline \multirow{2}{*}{2018.9 .15} & 4.2 & $560.29 \mathrm{ab}$ & $546.14 \mathrm{a}$ & $375.86 \mathrm{~b}$ \\
& 8.4 & $568.00 \mathrm{ab}$ & $351.43 \mathrm{c}$ & $353.43 \mathrm{c}$ \\
& 84 & $572.43 \mathrm{a}$ & $386.71 \mathrm{ab}$ & $474.43 \mathrm{a}$ \\
& 168 & $485.29 \mathrm{~b}$ & $374.86 \mathrm{~b}$ & $385.57 \mathrm{ab}$ \\
& 252 & $341.29 \mathrm{bc}$ & $409.71 \mathrm{a}$ & $365.57 \mathrm{bc}$ \\
\hline \multirow{2}{*}{2018.9 .22} & 0 & - & $161.71 \mathrm{c}$ & $109.14 \mathrm{~d}$ \\
& 8.2 & - & $540.86 \mathrm{ab}$ & $599.57 \mathrm{a}$ \\
& 8.4 & - & $498.43 \mathrm{~b}$ & $448.14 \mathrm{bc}$ \\
& 168 & - & $572 \mathrm{a}$ & $422.71 \mathrm{c}$ \\
& 252 & - & $578.86 \mathrm{a}$ & $452.14 \mathrm{~b}$ \\
\hline
\end{tabular}

Note: The data in the table are the original data and have not been converted. Means within a column followed by the same letter are not significantly different according to LSD at $p=0.05$. The data were from WSP samples and that thus the data may differ from the actual values on the leaves.

Table 2 Effects of the dosage of alkyl ethyl sulfonate on the coefficient of variation of droplet distribution

\begin{tabular}{|c|c|c|c|c|c|c|c|c|}
\hline \multirow{3}{*}{$\begin{array}{c}\text { Alkyl ethyl sulfonate } \\
\text { dosage } \\
/ \mathrm{g} \text { a.i. } \cdot \mathrm{hm}^{-2}\end{array}$} & \multicolumn{7}{|c|}{$C V / \%$} & \multirow{3}{*}{ Average } \\
\hline & \multicolumn{4}{|c|}{ First spraying } & \multicolumn{3}{|c|}{ Second spraying } & \\
\hline & Upper layer & Middle layer & Lower layer & Average & Middle layer & Lower layer & Average & \\
\hline 0 & 65.12 & 31.67 & 23.87 & 40.22 & 54.30 & 29.50 & 41.90 & 41.06 \\
\hline 4.2 & 53.63 & 68.39 & 43.75 & 55.25 & 42.30 & 38.77 & 40.54 & 47.90 \\
\hline 8.4 & 54.17 & 60.26 & 53.12 & 55.85 & 54.19 & 55.66 & 54.93 & 55.39 \\
\hline 84 & 69.03 & 88.28 & 88.31 & 81.87 & 61.07 & 67.83 & 64.45 & 73.16 \\
\hline 168 & 39.17 & 75.73 & 118.44 & 77.78 & 42.23 & 66.45 & 54.34 & 66.06 \\
\hline 252 & 78.18 & 55.05 & 91.66 & 74.96 & 56.53 & 49.02 & 52.77 & 63.87 \\
\hline
\end{tabular}

\subsubsection{Droplet contact angle}

Contact angle is the main indicator to measure the effect of droplets on the spreading and retention of cotton leaves. Figure 5 showed the effect of alkyl ethyl sulfonate dosage on pesticide droplet contact angle. When the added dosage of alkyl ethyl sulfonate was $8.4 \mathrm{~g}$ a.i. $/ \mathrm{hm}^{2}$, displayed the lowest contact angle. The contact angle could be significantly increased without the addition of alkyl ethyl sulfonate and the highest dose of alkyl ethyl sulfonate. This result is consistent with the results of droplet coverage and droplet density. 

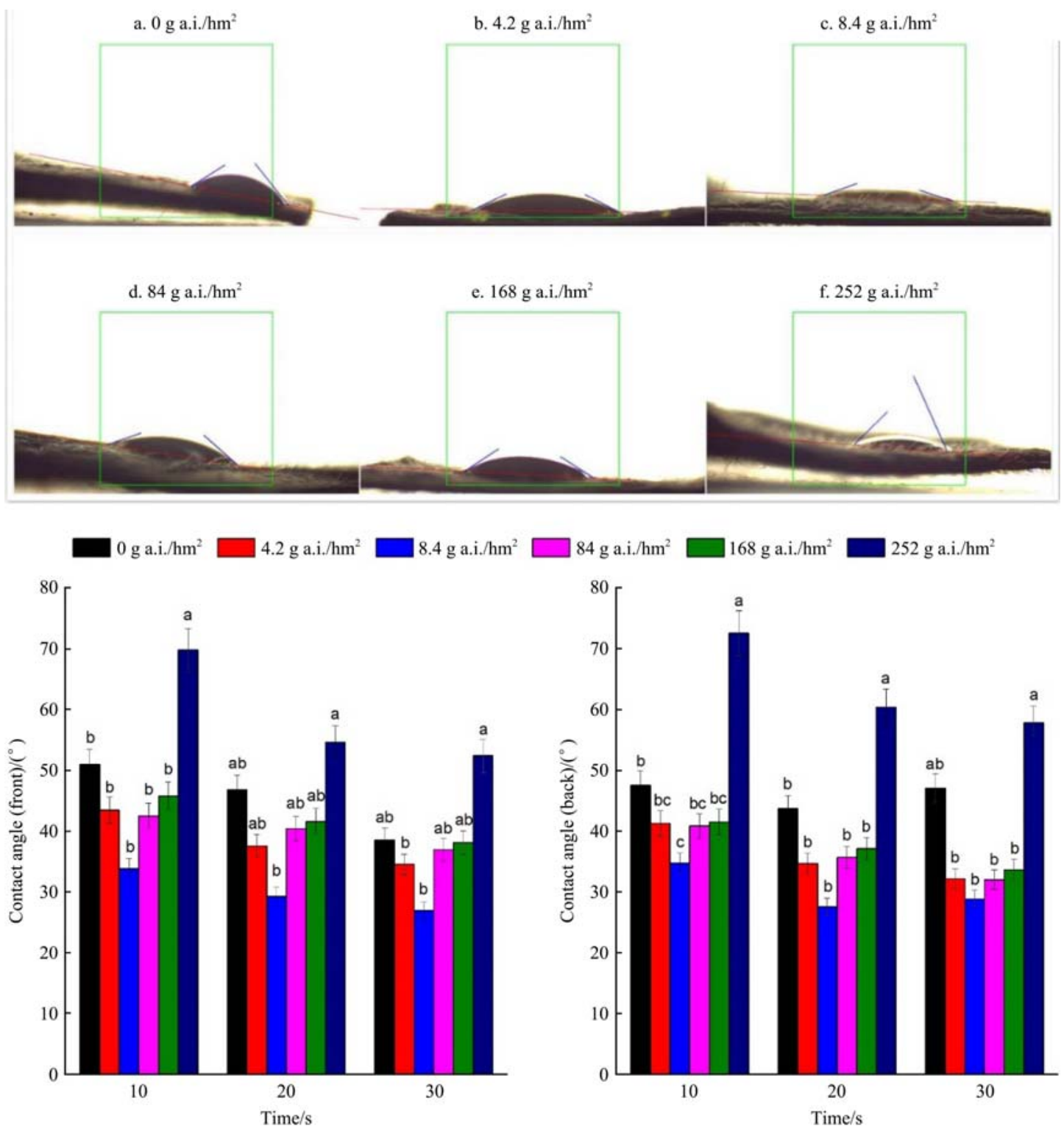

Figure 5 Effects of alkyl ethyl sulfonate dosage on contact angle

It was found that with the increase of adjuvants ratio, the decrease degree of contact angle was lower and even higher. This showed that in practical application, the excessive addition of adjuvants is meaningless ${ }^{[40]}$. This is consistent with our research conclusion. In order to obtain better contact angle of defoliant droplet on cotton leaves, the dosage of alkyl ethyl sulfonate should not exceed $8.4 \mathrm{~g}$ a.i. $/ \mathrm{hm}^{2}$.

\subsection{Defoliation and boll opening}

\subsubsection{Defoliation}

According to the results of spray deposition and high cotton plant density, the droplet coverage rate of the UAV spray treatments is low in the middle and bottom layers with single round spraying due to dense cotton leaves in the upper canopy, which blocks the descent of the droplets. Hence, second-round harvest aid spraying was carried out after seven days. The effect of added alkyl ethyl sulfonate on cotton defoliation was shown in Figure 6. Leaf abscission began to form four days after the first spraying, and the alkyl ethyl sulfonate had a considerable effect on the defoliation effect. For the upper layer of the cotton canopy, only the $8.4 \mathrm{~g}$ a.i. $/ \mathrm{hm}^{2}$ treatment showed the worst defoliation efficacy; the other treatments were similar with the control treatment (without alkyl ethyl sulfonate, Figure 6a). For the middle layer of the cotton canopy, after 7,12 , and 15 days after spraying, the defoliation rate of the $4.2 \mathrm{~g}$ a.i. / ha alkyl ethyl sulfonate treatment was $95.98 \%, 96.81 \%$ and $98.17 \%$, respectively, which was significantly better than other dosages (Figure 6b). Due to the poor penetrability of the canopy sprayed by UAV, the defoliation of the lower layer of cotton canopy was significantly lower than that of the upper and middle canopies, and the defoliation effect of $4.2 \mathrm{~g}$ a.i. $/ \mathrm{hm}^{2}$ alkyl ethyl sulfonate treatment was slightly higher than that of others (Figure 6c). For the cotton canopy, four days after the spraying, the defoliation rate was more than $40 \%$ when treated with different dosages of alkyl ethyl sulfonate, and 15 days after spraying (nine days after the second spraying), the defoliation rate was more than $80 \%$ (Figure 6d). In general, the cotton canopy demonstrated the highest defoliation rate when treated with $4.2 \mathrm{~g}$ a.i. $/ \mathrm{hm}^{2}$ alkyl ethyl sulfonate. Comparing with the information of droplet deposition, it could be found that $4.2 \mathrm{~g}$ a.i. $/ \mathrm{hm}^{2}$ alkyl ethyl sulfonate treatment had the best droplet coverage rate, droplet density and droplet size. The results were consistent with the defoliation rate. It also showed that the large diameter droplets could increase the retention of defoliant on cotton leaves by reducing drift and evaporation, thus increasing the defoliation effect. 


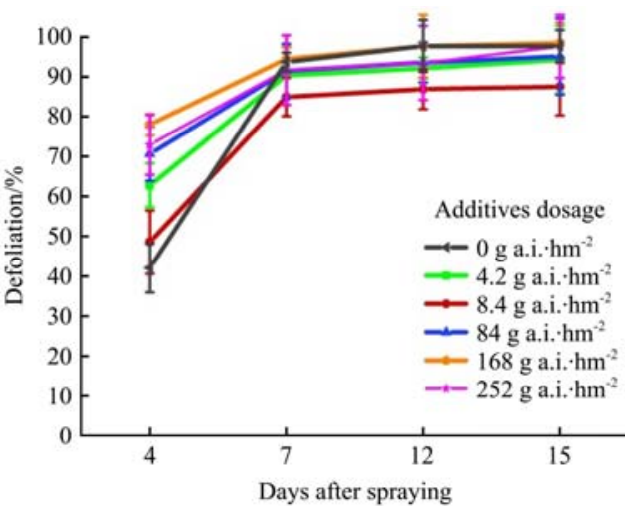

a. Cotton upper layer

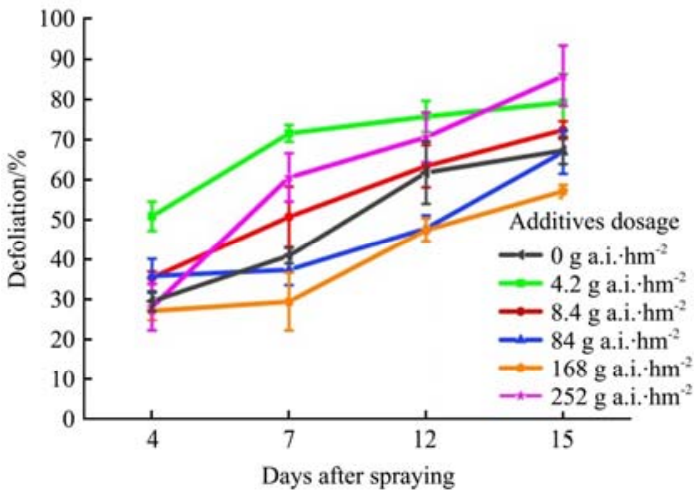

c. Cotton lower layer

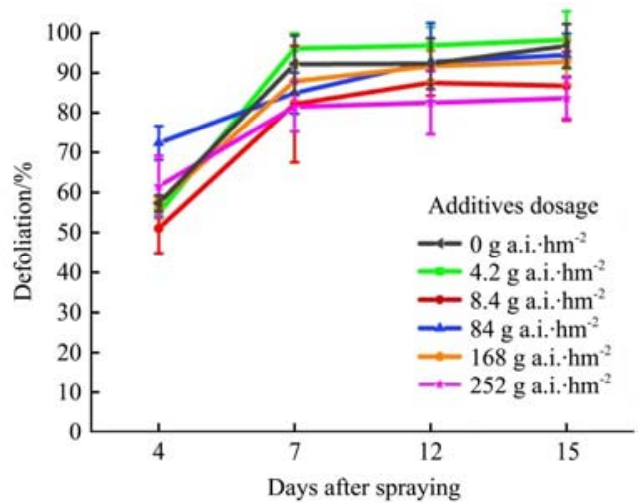

b. Cotton middle layer

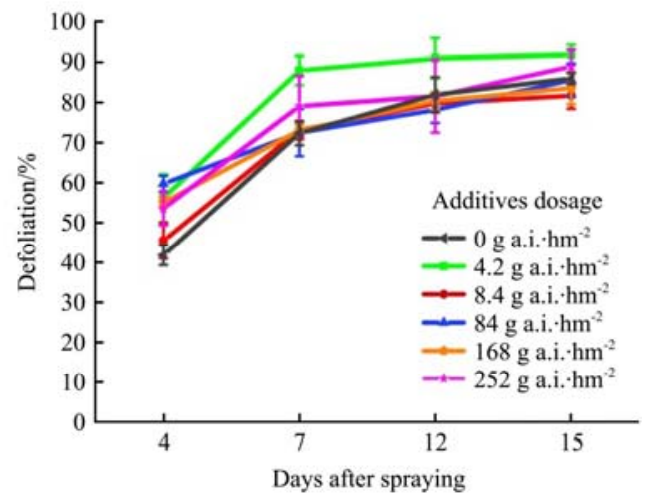

d. Cotton total layer

Figure 6 Effects of defoliant supporting adjuvant alkyl ethyl sulfonate dosage on defoliation and boll opening

\subsubsection{Boll opening}

Compared with the control, the cotton boll opening rate was significantly improved by adding alkyl ethyl sulfonate (Table 3). Four days after spraying, the boll opening rate of control treatment was $41.97 \%$, and that of $168 \mathrm{~g}$ a.i. $/ \mathrm{hm}^{2}$ alkyl ethyl sulfonate treatment was $54.61 \%$, which was consistent with the results of high droplet coverage and defoliation rate. Seven and twelve days after spraying, the boll opening rate of $168 \mathrm{~g}$ a.i./ $\mathrm{hm}^{2}$ alkyl ethyl sulfonate treatment both showed the best boll opening effect. Interestingly, fifth days after spraying, the boll opening rate of $4.2 \mathrm{~g}$ a.i. $/ \mathrm{hm}^{2}$ alkyl ethyl sulfonate treatment increased sharply, reached $85.27 \%$, which was no significant difference with $168 \mathrm{~g}$ a.i. $/ \mathrm{hm}^{2}$ treatment.

\subsection{Cotton yield characteristics and fiber quality}

The effects of alkyl ethyl sulfonate on cotton yield and quality factors are shown in Table 4. Compared with the control, the cotton boll weight (BW) increased after the addition of alkyl ethyl sulfonate, of which all alkyl ethyl sulfonate treatment reached significant levels. All alkyl ethyl sulfonate had no effect on upper half mean length (UHML), uniformity index (UI), breaking strength (Str) and maturity rate (MR) of cotton fiber quality factors. $84 \mathrm{~g}$ a.i./ $\mathrm{hm}^{2}$ alkyl ethyl sulfonate treatment had significant effect on micronaire (Mic), $4.2 \mathrm{~g}$ a.i. $/ \mathrm{hm}^{2}$ alkyl ethyl sulfonate treatment had little effect on short fiber index (SFI). Previous studies showed that spraying defoliants had significant effects on Boll and fiber development ${ }^{[6]}$. No direct report on the impact of alkyl ethyl sulfonate on cotton yield and fiber quality has been published.

Table 3 Effects of alkyl ethyl sulfonate dosage on cotton boll opening

\begin{tabular}{cccccc}
\hline \multirow{2}{*}{$\begin{array}{c}\text { Alkyl ethyl sulfonate dosage } \\
\text { g a. i.'hm } \text { h }^{-2}\end{array}$} & \multicolumn{5}{c}{ Days after spraying } \\
\cline { 2 - 6 } & 0 & 4 & 7 & 12 & 15 \\
\hline 0 & $36.32 \mathrm{~b}$ & $41.97 \mathrm{ab}$ & $43.55 \mathrm{c}$ & $55.47 \mathrm{c}$ & $74.76 \mathrm{~b}$ \\
4.2 & $38.87 \mathrm{~b}$ & $47.78 \mathrm{~b}$ & $55.62 \mathrm{c}$ & $66.85 \mathrm{bc}$ & $85.27 \mathrm{ab}$ \\
8.4 & $42.10 \mathrm{a}$ & $50.88 \mathrm{ab}$ & $57.51 \mathrm{~b}$ & $70.91 \mathrm{~b}$ & $83.85 \mathrm{ab}$ \\
84 & $41.29 \mathrm{ab}$ & $47.13 \mathrm{ab}$ & $55.91 \mathrm{~b}$ & $75.18 \mathrm{ab}$ & $84.35 \mathrm{ab}$ \\
168 & $45.65 \mathrm{a}$ & $54.61 \mathrm{a}$ & $72.90 \mathrm{a}$ & $80.46 \mathrm{a}$ & $88.38 \mathrm{a}$ \\
252 & $40.98 \mathrm{~b}$ & $44.36 \mathrm{~b}$ & $61.45 \mathrm{ab}$ & $68.86 \mathrm{bc}$ & $75.94 \mathrm{~b}$
\end{tabular}

Note: means within a column followed by the same letter are not significantly different according to LSD at $p=0.05$.

Table 4 Effects of alkyl ethyl sulfonate dosage on cotton fiber quality and yield

\begin{tabular}{|c|c|c|c|c|c|c|c|c|}
\hline $\begin{array}{l}\text { Alkyl ethyl sulfonate dosage } \\
\qquad / \mathrm{g} \text { a. } \mathrm{i} \cdot \mathrm{hm}^{-2}\end{array}$ & $\mathrm{BW} / \mathrm{g}$ & $\mathrm{UHML} / \mathrm{mm}$ & $\mathrm{UI} \%$ & Mic & $\mathrm{Str} / \mathrm{cN} \cdot \operatorname{tex}^{-1}$ & Elg $/ \%$ & MR & SFI \\
\hline 0 & $4.66 \mathrm{c}$ & $28.76 \mathrm{a}$ & $84.05 \mathrm{a}$ & $4.68 \mathrm{ab}$ & $29.35 \mathrm{a}$ & $6.85 \mathrm{a}$ & $0.84 \mathrm{a}$ & $7.70 \mathrm{ab}$ \\
\hline 4.2 & $5.72 \mathrm{ab}$ & $28.35 \mathrm{a}$ & $84.75 \mathrm{a}$ & $4.65 \mathrm{ab}$ & $28.75 \mathrm{ab}$ & $6.85 \mathrm{a}$ & $0.84 \mathrm{a}$ & $7.45 b$ \\
\hline 8.4 & $5.96 \mathrm{ab}$ & $29.48 \mathrm{a}$ & $84.85 \mathrm{a}$ & $4.74 b$ & $29.45 \mathrm{a}$ & $6.95 \mathrm{a}$ & $0.84 \mathrm{a}$ & $7.40 \mathrm{bc}$ \\
\hline 84 & $5.05 \mathrm{~b}$ & $28.42 \mathrm{a}$ & $84.15 \mathrm{a}$ & $4.23 \mathrm{c}$ & $29.50 \mathrm{a}$ & $6.85 \mathrm{a}$ & $0.83 a b$ & $7.65 \mathrm{~b}$ \\
\hline 168 & $6.23 \mathrm{a}$ & $27.58 \mathrm{ab}$ & $84.40 \mathrm{a}$ & $4.79 a$ & $29.45 \mathrm{a}$ & $6.80 \mathrm{a}$ & $0.85 a$ & $7.70 \mathrm{ab}$ \\
\hline 252 & $5.63 \mathrm{ab}$ & $28.25 \mathrm{a}$ & $83.35 \mathrm{ab}$ & $4.89 \mathrm{a}$ & $29.60 \mathrm{a}$ & $6.75 \mathrm{ab}$ & $0.85 \mathrm{a}$ & $8.30 \mathrm{a}$ \\
\hline
\end{tabular}

Note: a: BW, Boll weight; UHML, Upper Half Mean Length; UI, Uniformity Index; Mic, Micronaire; Str, Breaking Strength; Elg, Elongation rate; MR, Maturity Rate; SFI, Short Fiber Index. 


\section{Conclusions}

In this study, six dosages of alkyl ethyl sulfonate adjuvants were used for defoliants spraying by UAV. The uniformity of the deposition, droplets penetrability, characteristics of the deposition, defoliation rate and boll opening rate were compared in this research. The dosage of alkyl ethyl sulfonate had a great influence on defoliant droplet deposition. Added with lower dosage alkyl ethyl sulfonate, the droplet distribution uniformity was much better than that of moderate and high dosage alkyl ethyl sulfonate. Addition with lower dosage alkyl ethyl sulfonate (4.2 $\mathrm{g}$ a.i. $/ \mathrm{hm}^{2}$, which was the one-sixtieth of the recommended dosage in the field) could significantly increase the droplets coverage rate, and showed better defoliation and boll opening effects. Therefore, the experiment demonstrated the feasibility of the alkyl ethyl sulfonate dosage could be reduced. This not only reduced the environmental pollution caused by excessive alkyl ethyl sulfonate, but also avoids the waste of resources.

\section{Acknowledgments}

We acknowledge that this work was financially supported by the National Natural Science Foundation of China (31960566), Xinjiang Production and Construction Corps International Science and Technology Cooperation Program (2017BC001), and National Key Research and Development Program of China (2016YFD0200700). The authors are grateful to XAG Co., Ltd. for providing plant protection unmanned aerial vehicle.

\section{[References]}

[1] Yu S X. The Development of Cotton Production in the Recent Hundred Years of China. J of Agriculture, 2018, 8(1): 85-91. (in Chinese)

[2] National Bureau of Statistics. Announcement of the National Bureau of Statistics on Cotton Production in 2018. Available online: http://www.stats.gov.cn/tjsj/zxfb/201812/t20181229 1642170.html Accessed on [2018-12-29].

[3] Yu S X, Zhang L, Feng W J. Study on Strategy of Large Scale, Mechanization, Informationization, Intelligence and Social Services for Cotton Production. Eng Sci, 2016, 18(1): 137-148. (in Chinese)

[4] Statistics Bureau of Xinjiang production and Construction Corps. National economic and social development statistics bulletin of Xinjiang production and Construction Corps in 2018. http://www.xjbt.gov.cn/c/2019-03-22/7228412.shtml Accessed on [2019-03-22]

[5] Gormus O, Kurt F, El Sabagh A. Impact of Defoliation Timings and Leaf Pubescence on Yield and Fiber Quality of Cotton. J Agr Sci Tech, 2017, 19:903-915.

[6] Karademir E, Karademir C, Basbag S. Determination the Effect of Defoliation Timing on Cotton Yield and Quality. J Cent Eur Agr, 2008, 8 : 357-361.

[7] Guo X X and Zeng W. A study on relationship between temperature and cotton boll development in Xinjiang. Crop J, 1989, 15: 202-212.

[8] Çôpur O, Demirel U, Polat R., and Gür M A. Effect of Different Defoliants and Application Times on the Yield and Quality Components of Cotton in Semi-arid Conditions. Afr J Biotechnol, 2010, 9: 2095-2100. doi: 10.4314/ajb.v9i14.

[9] Tian J S, Zhang X Y, Yang Y L, Yang C X, Xu S Z, Zuo W Q, Zhang W F, Dong H Y, Jiu X L, Yu Y C. 2017. How to reduce cotton fiber damage in the Xinjiang China. Ind Crop Prod, 2017, 109: 803-811. doi: 10.1016/j.indcrop.2017.09.036

[10] Zhang L J, Wang Z J, Peng L. Quality comparison between mechanical harvesting cotton and hand harvesting cotton based on statistic analysis. J Chin Agric Mechan, 2013, 34(6): 89-94.

[11] Qin W C, Xue X Y, Cui L F, Zhou Q Q, Xu Z F, Chang F L. Optimization and test for spraying parameters of cotton defoliant sprayer. Int J Agric \& Biol Eng 2016, 9: 63-72. doi: 10.3965/j.ijabe.20160904.2125

[12] Meng Y H, Song J L, Lan Y B, Mei G Y, Liang Z J, Han Y X. Harvest aids efficacy applied by unmanned aerial vehicles on cotton crop. Ind Crop Prod, 2019, 140:111645. doi: 10.1016/j.indcrop.2019.111645

[13] Xiao Q G, Xin F, Lou Z X, Zhou T T, Wang G B, Han X Q, Lan Y B, Fu W. Effect of aviation spray adjuvants on defoliant droplet deposition and cotton defoliation efficacy sprayed by unmanned aerial vehicles. Agronomy, 2019, 9: 217 . doi: 10.3390/agronomy9050217

[14] Xin F, Zhao J, Zhou Y T, Wang G B, Han X Q, Fu W, Deng J Z, Lan Y B. Effects of Dosage and Spraying Volume on Cotton Defoliants Efficacy: A Case Study Based on Application of Unmanned Aerial Vehicles. Agronomy, 2018, 8: 85. doi: 10.3390/agronomy8060085

[15] Hu H Y, Ren X L, Ma X Y, Ma Y J, Jiang W L, Wang D, Song X P, Ma, Y. Spraying Technology of Plant Protection Unmanned Aerial Vehicle for Cotton Defoliant. China Cotton, 2018, 45: 43-44. (in Chinese)

[16] Lan Y B and Wang G B. Development Situation and Prospect of Plant Protection UAV in China. Agr Eng Tech 2018, 38: 17-27. (in Chinese)

[17] Lan Y B, Chen S D. Current status and trends of plant protection UAV and its spraying technology in China. Int. J Precis Agric Aviat, 2018, 1(1) $1-9$.

[18] Wen C J, Yang J R, Han J, Shao S Y. Effect comparison of cotton defoliant spraying on plant protection UAV and motor vehicle. Nongcunkeji, 2018, 3: 26-27. (in Chinese)

[19] Ma Y, Ren X L, Meng Y H, Song J L, Ma D Y, Liu Z, Fu W, Jiang W L, Wang D, Wang Z G, Lan Y B. Review on Result of Spraying Defoliant by Unmanned Aerial Vehicles in Cotton Field of Xinjiang. China Cotton, 2016, 43: 16-20. (in Chinese)

[20] Wang Z, Feng H Z, Wang L, Ma X Y, Guo C Q, Xiao H B, Huang Q. Effects Comparison of Different Defoliants Applied by Dajiang MG-1S Unmanned Air Vehicle in Cotton Field. China Cotton, 2018, 45: 27-28, 46. (in Chinese)

21] $\mathrm{Hu} \mathrm{H}$ Y, Ren X L, Ma X Y, Jiang W L, Ma Y J, Wang D, Ma Y. Comparison of Defoliation Effects between Unmanned Air Vehicle Spraying and Artificial Spraying in Cotton Field. China Cotton, 2018, 45: 13-15, 19. (in Chinese)

[22] Zhang K P, Deng X J, Wang C Y. Effects of different composite chemicals on cotton ripening and defoliation sprayed by UAV. Agrochemicals, 2017, 56(08): 619-623. (in Chinese)

[23] Wen C J, Yang J R, Han J, Shao A Y. Comparison of effects of plant protection drones and motor vehicle spraying defoliants. Rural Science \& Technology, 2018, (03): 26-27. (in Chinese)

[24] Nguyen G V. Monoalkyl Sulfosuccinates In Pesticide Formulations And Applications. USA, 2016, US20120172229 A1. doi: US20120172229 A1

[25] Elder D P, Delaney Ed, Teasdale A, Eyley S, Reif V D, Jacq K, Facchine K L, Oestrich R S, Sandra P, David F. The Utility of Sulfonate Salts in Drug Development. J Pharm Sci, 2010, 99: 2948-2961. doi: 10.1002/ jps. 22058

[26] Bai L, Wang Y, Liu X C, Zhou Y W, Niu J P. Effect of Alkyl Tail Length of Alpha Olefin Sulfonates on Foam Properties. Tenside Surfact Det, 2018, 55: 484-490. doi: 10.3139/113.110594

[27] Sol-Sánchez M, Moreno-Navarro F, Rubio-Gámez M C. Study of Surfactant Additives for the Manufacture of Warm Mix Asphalt: From Laboratory Design to Asphalt Plant Manufacture. Appl Sci, 2017, 7: 745 doi: 10.3390/app7070745

[28] Tang A Y L, Wang Y M, Lee C H, Kan C W. Computer Color Matching and Levelness of PEG-Based Reverse Micellar Decamethyl cyclopentasiloxane (D5) Solvent-Assisted Reactive Dyeing on Cotton Fiber. Appl Sci, 2017, 7: 682. doi: 10.3390/app7070682

[29] Wibbertmann A, Mangelsdorf I, Gamon K, Sedlak R. Toxicological properties and risk assessment of the anionic surfactants category: Alkyl sulfates, primary alkane sulfonates, and $\alpha$-olefin sulfonates. Ecotox Environ Safety, 2011, 74: 1089-1106. doi: 10.1016/j.ecoenv.2011.02.007

[30] Mungray A K, Kumar P. Fate of linear alkylbenzene sulfonates in the environment: A review. Int Biodeter Biodegr, 2009, 63: 984-987. doi: 10.1016/j.ibiod.2009.03.012

[31] Wang G B, Lan Y B, Yuan H Z, Qi H X, Chen P C, Ouyang F, Han Y X. Comparison of Spray Deposition, Control Efficacy on Wheat Aphids and Working Efficiency in the Wheat Field of the Unmanned Aerial Vehicle with Boom Sprayer and Two Conventional Knapsack Sprayers. Appl Sci, 2019, 9: 218. doi: 10.3390/app9020218

[32] Zhu H P, Salyani M, Fox R D. A portable scanning system for evaluation of spray deposit distribution. Comput Electron Agr, 2011, 76: 38-43. doi: 10.1016/j.compag.2011.01.003

[33] Berger-Neto A, Jaccoud-Filho D S, Wutzki C R. Effect of spray droplet 
size, spray volume and fungicide on the control of white mold in soybeans. Corp Prot, 2017, 92: 190-197. doi: 10.1016/j.cropro.2016.10.016

[34] Wang G B, Lan Y B, Qi H X, Chen P C, Hewitt A J, Han Y X. Field evaluation of an unmanned aerial vehicle (UAV) sprayer: Effect of spray volume on deposition and the control of pests and disease in wheat. Pest Manag Sci, 2019, 9: 218. doi: 10.3390/app9020218

[35] Yuan H Z, Wang G B. Effect of droplet size and deposition density on field efficacy of pesticides. Plant Prot, 2015, 41(6): 9-16.

[36] Zhang R R, Zhang Z, Xu G, Chen L P, Hewitt A J. Effect of spray adjuvant types and concentration on nozzle atomization. Transactions of the CSAE, 2018, 34(20): 36-43. (in Chinese)

[37] Lan Y B, Hoffmann W C, Fritz B K, Martin D E, Lopez Jr J D. Spray drift mitigation with spray mix adjuvants. Applied Engineering in
Agriculture, 2008, 24(1): 5-10. doi: 10.13031/2013.24157

[38] Li J, Chen W T, Xu Y, Wu X M. Comparative effects of different types of tank mixed adjuvants on the efficacy, absorption and translocation of cyhalofop-butyl in barnyardgrass (Echinochloa crus-galli [L.] Beauv.). Weed Biology and Management, 2016, 16: 80-89. doi: 10.1111/ wbm. 12095

[39] Civil Aviation Administration of China. Civil Aviation Industry Standards of the People's Republic of China: Agricultural aviation operation quality technical indicators: Part 1: Spraying operation. Beijing: China Civil Aviation Administration, 2016. (in Chinese)

[40] Yang X, Du Y K, Tian W J, Fan H X, Du Q, Dang Y J. Influences of Surfactants on Contact Angle of Pharmaceutical Excipients. China Pharmacist, 2017, 20(11): 2090-2092. (in Chinese) 